\title{
Epidemiology of cervical human papillomavirus (HPV) infection and squamous intraepithelial lesions (SIL) among a cohort of HIV-infected and uninfected Ghanaian women
}

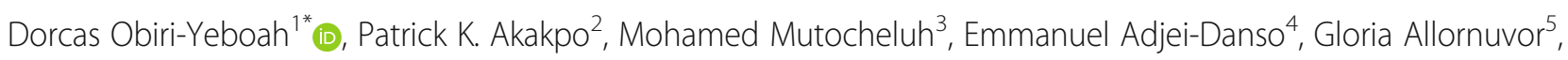
Daniel Amoako-Sakyi ${ }^{1}$, Yaw Adu-Sarkodie ${ }^{3}$ and Philippe Mayaud ${ }^{6}$

\begin{abstract}
Background: There is limited data in Ghana on the epidemiology of HPV and cervical neoplasia and their associations with HIV. This study aimed to compare among HIV-1 seropositive and HIV-seronegative Ghanaian women: (1) the prevalence, genotype distribution and risk factors associated with cervical HPV infection; and (2) the prevalence and risk factors associated with abnormal cervical cytology.

Methods: A comparative frequency-matched study was conducted in a systematic sample of women aged $\geq 18$ years attending HIV and general outpatient clinics in Cape Coast Teaching Hospital, Ghana. Participants were interviewed and cervical samples collected for HPV genotyping (Seegene Anyplex-II HPV28) and cytological testing.

Results: Overall, 333 women were recruited, 163 HIV-1 seropositive and 170 HIV-seronegative women of mean age 43.8 years $(S D \pm 9.4)$ ) and 44.3 years (SD \pm 12.8 ), respectively. The prevalence of 14 high-risk (hr) HPV genotypes was higher among HIV-1 seropositive women $(65.6 \%$ vs. 30.2\%, $P<0.0001)$, as was proportion with multiple hr.-HPV infections $(60.6 \%$ vs. $21.3 \%, P<0.0001)$. HPV35 was the most prevalent hr.-HPV genotype in both groups (11.9\% and 5.3\%). The main factors associated with hr.-HPV infection were age for HIV-positive women and circumcision status of main sexual partner for both HIV-negative and positive women.

Abnormal cervical cytology prevalence was higher among HIV-1 seropositive women (any SIL: 14.1\% Vs. 1.2\%, $P<0$. 0001 ; low-grade SIL [LSIL]: $4.9 \%$ vs. $0.6 \%, P=0.02$; high-grade SIL: $1.8 \%$ vs. $0 \%, P=0.07$ ). Among HIV-1 seropositive women, number of pregnancies and CD4+ cell count were associated with LSIL+ cytology. There was strong association between LSIL+ abnormalities and HPV35 (aOR = 4.7, 95\%Cl: 1.3-17.7, $P=0.02$ ).
\end{abstract}

Conclusions: HIV-1 infected women bear significant burden of HPV infection and related disease. Prevention and screening programmes should be specifically deployed for this population in Ghana.

Keywords: Human papillomavirus (HPV), Genotyping, Squamous intraepithelial lesions (SIL), Cervical cancer, Human immunodeficiency virus (HIV), Ghana

\footnotetext{
*Correspondence: d.obiri-yeboah@uccsms.edu.gh; castella.oy@gmail.com 'Department of Microbiology and Immunology, School of Medical Sciences, University of Cape Coast, Cape Coast, Ghana

Full list of author information is available at the end of the article
} 


\section{Background}

Persistent infection with genital human papillomavirus (HPV) is causally linked with many genital cancers, including cervical cancer $[1,2]$. Genital HPV genotypes are further categorized broadly into low-risk (lr) and high-risk (hr) types based on their oncogenic potential. Persistence of hr.-HPV in the transformation zone of about $10 \%$ of infected persons may lead over time to squamous intraepithelial lesions (SIL) or cervical intraepithelial neoplasia (CIN) and invasive cervical carcinoma (ICC).

Co-infection with HPV has implications for HIV-infected women and their health care providers. HIV increases the risk of HPV persistence and development of associated cervical lesions [3]. In particular, low CD4+ T-lymphocyte counts may increase the risk of recurrence [4, 5], whilst higher $\mathrm{CD} 4+$ cell counts may promote HPV clearance, highlighting the role of immunity in the development of cervical disease [6]. The role of antiretroviral therapy (ART) is more complex. By decreasing HIV plasma viral load and restoring immunity, ART is expected to have benefits in reducing HPV-associated clinical conditions among HIVinfected women [7-9], especially among ART users with high adherence [10]. However, several studies have not reported such benefits of ART directly [11-13]. Improved survival among women living with HIV taking ART increases potential exposure time and may lead to higher cancer rates, underscoring the need for specific screening and management programmes in this high-risk population.

Other known risk factors of HPV acquisition, persistence and development of cervical lesions include age, age at first sexual activity, life time number of sexual partners [14-16], smoking [17], hormonal contraceptive use [18, 19], coinfection with other STIs $[20,21]$ and lack of circumcision of the male partner [22].

Forman et al. [23] have estimated the global adjusted HPV prevalence to be $11.7 \%$, with West Africa having the fourth highest with a prevalence of $19.6 \%$. Limited data on HPV and SIL/CIN epidemiology are available in Ghana from women attending gynaecological clinics. Brandful et al. [24] reported an HPV prevalence of 64.5\% among HIVseronegative pregnant women in Accra. Attoh et al. [25] in their study among 50 women diagnosed with cervical cancer in Ghana found cervical HPV DNA prevalence of $98 \%$, with HPV18 being the most predominant type (84\%) followed by HPV16 (24\%). Cervical cancer screening in the country is not systematically organized with some pilot implementation of the WHO-recommended visual inspection with acetic acid (VIA) [26], whilst cytological screening using the Papanicolaou (pap) method is becoming more available, albeit with associated significant costs and logistical challenges.

Since 2005, the use of HPV vaccines, first the bivalent and quadrivalent vaccines targeting HPV16 and 18 linked to $70 \%$ of invasive cancers (and low risk HPV 6 and 11), and recently the nonavalent vaccine targeting the same types plus five other hr. types (HPV31, 33, 45, 52 and 58), globally linked to $90 \%$ of cancers [27], has made primary prevention possible. These vaccines have been shown to be effective in preventing HPV infection and the development of genotype-specific HPV-associated clinical conditions [28-30]. In Ghana, a pilot HPV vaccination programme targeting school-going girls aged 9-13 was carried out in 2013 in selected regions using the quadrivalent vaccine. More detailed information on the prevalence and distribution of HPV genotypes associated with lesions in various patient groups in Ghana would help inform $\mathrm{HPV}$ vaccination and screening plans.

The objectives of this study were to compare between HIV-1 sero-positive and HIV sero-negative women in the Cape Coast Metropolis of Ghana: (1) the prevalence, genotype distribution and risk factors associated with $\mathrm{HPV}$ infection, and (2) the prevalence and risk factors associated with abnormal cervical cytology (ASCUS+).

\section{Methods \\ Study design and subjects}

This study was a comparative frequency-matched study conducted among women $\geq 18$ years attending the HIV or medical outpatient clinic of the Cape Coast Teaching Hospital (CCTH) in Ghana. A systematic sampling of every 5 th woman was used starting with a random sampling of the first woman. Women who were ineligible (previous total hysterectomy, pregnant or menstruating on that day), had the opportunity passed on to the next until a total of 10 women per day were selected. After recruitment, the study protocol was explained to each woman and written informed consent was then obtained.

Enrolled women then had their HIV status confirmed and then they answered a questionnaire in either English or the local language (Fante). This questionnaire gathered socio demographic characteristics of the women and then for HIV positive women, the HIV specific characteristics including use of ART, nadir CD4+ Tlymphocytes count, and WHO clinical staging were also obtained (Additional file 1).

\section{Sample collection}

Blood was drawn to perform HIV serology using the First Response Kit (Premier Medical Corporation Limited, India) to detect HIV-1 and HIV-2 antibodies, confirmed with the OraQuick kit (OraSure Technologies, USA), as per national guidelines. Counseling based on the results was done for all women and women found HIV-1 seropositive but not already in care were referred to the ART treatment center at CCTH. Participants underwent gynaecological examination with speculum, during which cervical swabs were collected from the ecto/endocervix targeting the squamocolumnar junction using a DNA PAP ${ }^{\mathrm{ma}}$ Cervical Sampler ${ }^{\mathrm{Tm}}$ 
and transported in the Swab Specimen Collection Kit (Qiagen, Gaithersburg, MD). Cervical smears were taken for cytology with a cervical brush and alcohol-fixed at the clinic. All women found to have LSIL+ cytology were referred to the gynaecologist for further evaluation and management.

\section{HPV DNA detection}

HPV genotyping was performed using the recently developed Anyplex ${ }^{\mathrm{m}}$ II HPV28 assay (Seegene, Seoul, Korea). The assay detects $28 \mathrm{HPV}$ genotypes including $19 \mathrm{~h}-\mathrm{HPV}$ types, of which 13 are considered carcinogenic (HPV16, 18, $31,33,35,39,45,51,52,56,58,59,68)$ and 6 possible carcinogenic (HPV26, 53, 66, 69, 73, 82), and 9 low-risk HPV types (HPV6, 11, 40, 42, 43, 44, 54, 61, 70), according to the Interagency for Research on Cancer (IARC) [31]. This assay has been compared with the Digene HC2 HPV DNA assay (Qiagen) and found to be analytically more sensitive in detecting the $13 \mathrm{~h}$-HPV types identifiable by both assays, in addition to having higher concordance with comprehensive genotyping based on sequencing analysis [32].

The isolation of nucleic acid was done by QIAamp DNA Mini kit (Qiagen, USA) following manufacturer's instructions. Extracted DNA samples were aliquoted and stored at $-20{ }^{\circ} \mathrm{C}$. The next step was the multiplex real time PCR using the Anyplex ${ }^{\mathrm{m}}$ II HPV28 (Seegene, Korea) following manufacturer's protocol with the CFX96 $^{\text {ma }}$ Real-time PCR System (Bio-Rad, USA). In brief, this involved preparation of a master mix which contained RNAase free water ( $5 \mu \mathrm{l}$ per sample), $4 \mathrm{X}$ Anyplex solution ( $5 \mu \mathrm{l}$ per sample) and 4X HPV28 TOM A or TOM B solutions ( $5 \mu \mathrm{l}$ per sample for each type). TOM A contained the primers for hr.-HPV genotypes, while TOM B contained primers for non hr.-HPV types. Both reactions were set up to run concurrently. To $15 \mu \mathrm{l}$ of reagents was added $5 \mu \mathrm{l}$ of the prepared DNA sample.

A set of 3 external positive controls and a negative control were included in each set to run with the samples. To be valid for any sample, both the internal and external controls must have expected result. When the external controls failed the whole set was invalid and no results were read. When the internal control for a sample failed, whilst all external controls were correct, that particular sample result was considered invalid and it tested again.

\section{Cervical cytology}

Following a standardized protocol for Papanicolaou (pap) staining, cervical smears were prepared in the laboratory and read by a consultant cytopathologist at $\mathrm{CCTH}$ using the Bethesda 2001 guidelines and the LAST guidelines [33, 34].

\section{Sample size and statistical analysis}

Sample size was calculated to allow comparisons of HIV-1 seropositive and HIV-seronegative women. Assumptions on HPV and cytological abnormality prevalence in each group were based on findings from different studies around the Africa region and sample size was powered to detect differences in the lowest frequency outcome (cytological abnormalities). Data analyses were performed using Stata version 13 software (STATA Corp, Texas USA).

A descriptive analysis of socio-demographic, behaviour and other relevant characteristics of the study population was done according to HIV serostatus. $P$-values were used to compare the parameters between the groups based on student's $t$-test for continuous variables or chi- square test for categorical variables. Bivariate analysis was done separately for the two study outcomes (HPV and cytological abnormalities) stratified by HIV serostatus.

Based on outcome frequency, associations are presented as prevalence or risk ratios (PR/RR) with 95\% confidence intervals (CI) for the HPV outcomes, and odds ratios (OR) and $95 \% \mathrm{CI}$ for the cytological abnormality outcomes. Variables with $P$-values $\leq 0.20$ and a priori factors like age were put in the model for multivariate analysis.

\section{Results \\ Study participants}

A total of 333 (163 HIV-1 seropositive and 170 HIVseronegative) women were recruited between July and December 2014. Participant characteristics are shown in Table 1. The mean age of participants was 43.8 (SD \pm 9.4 ) years for HIV-1-seropositive women and 44.3 years (SD $\pm 12.8)$ for HIV-seronegative women. Compared to HIVseronegative women, HIV-1 seropositive women were less educated, more frequently in unskilled occupations, without a current partner but with a larger number of lifetime partners. Smoking was rare in this population (about $2 \%$ overall) and hormonal contraceptive history infrequent $(39.3 \%$ and 42.4\%, in HIV-1 seropositive and HIV-seronegative women, respectively). Most male sexual partners (93\%) were circumcised, as expected in Ghana (Table 1).

The majority (57.1\%) of HIV-1 seropositive participants had been diagnosed with HIV less than 5 years ago with a median duration since HIV diagnosis of 4.3 years (interquartile range [IQR], 1.9-7.1). Most (79.1\%) were taking ART, $62 \%$ for longer than 2 years. The median nadir CD4 + count of women on ART and ART-naïve was 202 cells/ $\mathrm{mm}^{3}$ (IQR, 96-289) and 460 cells/ $\mathrm{mm}^{3}$ (IQR, 378-560), respectively (Table 2).

\section{Prevalence of HPV, genotype distribution and risk factors for hr.-HPV}

A total of 329/331 obtained samples were successfully genotyped using the Seegene Anyplex II HPV28 protocol, with two samples $(0.6 \%)$ giving invalid results. The overall HPV DNA prevalence was 75\% (120/160) among HIV-1 seropositive women and $42.6 \%$ (72/169) among HIVseronegative women $(p<0.0001)$. Compared to HIVseronegative women, HIV-1 seropositive women had a 
Table 1 Characteristics and laboratory findings of enrolled participants in Cape Coast, Ghana

\begin{tabular}{|c|c|c|c|}
\hline \multirow[t]{2}{*}{ VARIABLES } & \multirow{2}{*}{$\begin{array}{l}\text { HIV-1 seropositive }(N=163) \\
n(\%) \text {, or mean/median (SD or IQR) }\end{array}$} & \multirow{2}{*}{$\begin{array}{l}\text { HIV seronegative }(N=170) \\
n(\%) \text {, or mean/median (SD or IQR) }\end{array}$} & \multirow[t]{2}{*}{$P$-value } \\
\hline & & & \\
\hline Age, years & & & 0.03 \\
\hline Mean (SD) & $43.8(9.4)$ & $44.3(12.8)$ & \\
\hline$\leq 29$ & $11(6.8)$ & $21(12.4)$ & \\
\hline $30-59$ & $142(87.1)$ & $129(75.9)$ & \\
\hline$>60$ & $10(6.1)$ & $20(11.8)$ & \\
\hline Marital status & & & $<0.0001$ \\
\hline Currently with a regular sexual partner & $70(42.9)$ & $126(74.1)$ & \\
\hline Currently without a regular sexual partner & $93(57.1)$ & $44(25.9)$ & \\
\hline Education & & & $<0.0001$ \\
\hline No formal education & $40(24.5)$ & $28(16.5)$ & \\
\hline Up to secondary school level & $117(71.8)$ & $75(44.1)$ & \\
\hline Tertiary level & $6(3.7)$ & $67(39.4)$ & \\
\hline Employment & & & $<0.0001$ \\
\hline Unemployed & $14(8.6)$ & $14(8.2)$ & \\
\hline Unskilled occupation & $137(84.1)$ & $89(52.4)$ & \\
\hline Skilled occupation & $12(7.4)$ & $67(39.4)$ & \\
\hline Age at first sex, years Categorical & & & 0.16 \\
\hline Median (IQR) & $18(17-20)$ & $19(18-21)$ & \\
\hline$\leq 15$ & $7(4.3)$ & $6(3.5)$ & \\
\hline $16-20$ & $127(77.9)$ & $119(70.0)$ & \\
\hline$\geq 21$ & $29(17.8)$ & $45(26.5)$ & \\
\hline Lifetime no. sexual partners & & & 0.004 \\
\hline Median & $3(2-4)$ & $3(2-3)$ & \\
\hline 1 & $11(6.8)$ & $31(18.2)$ & \\
\hline $2-5$ & $139(85.3)$ & $131(77.1)$ & \\
\hline$>5$ & $13(8.0)$ & $8(4.7)$ & \\
\hline Circumcision main/current partner & & & 0.90 \\
\hline Circumcised & $153(93.9)$ & $159(93.5)$ & \\
\hline Not circumcised & $10(6.1)$ & $11(6.5)$ & \\
\hline Smoking & & & 0.09 \\
\hline Ever/Current & $5(3.1)$ & $1(0.6)$ & \\
\hline Never smoked & $158(96.9)$ & 169 (99.4) & \\
\hline Hormonal contraception & & & 0.57 \\
\hline Ever/Current & $64(39.3)$ & $72(42.4)$ & \\
\hline Never used & $99(60.7)$ & $98(57.6)$ & \\
\hline Cytology & & & $<0.0001$ \\
\hline Normal & $140(85.9)$ & $168(98.8)$ & $<0.0001$ \\
\hline ASCUS & $12(7.4)$ & $1(0.6)$ & 0.001 \\
\hline LSIL & $8(4.9)$ & $1(0.6)$ & 0.02 \\
\hline HSIL/ASC-H & $3(1.8)$ & $0(0)$ & 0.07 \\
\hline HPV DNA & $120 / 160(75.0)$ & 72/169 (42.6) & $<0.0001$ \\
\hline
\end{tabular}


Table 2 Clinical characteristics of 163 HIV-1 seropositive women at enrolment

\begin{tabular}{ll}
\hline VARIABLES & $\mathrm{n}(\%)$ or median (IQR) \\
\hline Duration of HIV diagnosis, years $(N=163)$ & \\
Median & $4.3(1.9-7.0)$ \\
$<5$ & $93(57.1)$ \\
$\geq 5$ & $70(42.9)$ \\
ART status ( $=163)$ & \\
Not on ART & $34(20.9)$ \\
$\leq 2$ years & $28(17.1)$ \\
$>2$ years on ART & $101(62.0)$ \\
WHO clinical stage $(N=159)$ & \\
Stage I \& II & $80(50.3)$ \\
Stage III \& IV & $79(49.7)$ \\
Nadir CD4+ count, cells $/ \mathrm{mm}^{3}(\mathrm{~N}=155)$ & \\
Median & $246(125-398)$ \\
$<200$ & $63(40.7)$ \\
$200-349$ & $49(31.6)$ \\
$350-500$ & $22(14.2)$ \\
$>500$ & $21(13.6)$ \\
\hline
\end{tabular}

$A R T$ antiretroviral therapy, IQR interquartile range

higher prevalence of hr.-HPV genotypes $(65.6 \%$ vs. $30.2 \%$, $P<0.0001)$, multiple HPV infections $(60.6 \%$ vs. $21.3 \%$, $P<0.0001)$, HPV16 and/or 18 infection $(21.3 \%$ vs. $2.4 \%$, $P<0.0001)$, or infection with hr.-HPV types included in the nonavalent vaccine (i.e. HPV16/18/31/33/45/52/58/6/ 11) $(55.6 \%$ vs. $17.2 \%, P<0.0001)$ (Table 3$)$. The most prevalent hr.-HPV genotypes among HIV-1 seropositive women in this study were HPV35 (11.9\%), 52 (11.9\%), 58 (11.3\%), $16(10.6 \%)$ and $18(10.6 \%)$, whereas among HIV-negative women the most prevalent types were HPV35 (5.3\%), 58 (4.1\%), 33 (4.1\%), 56 (3.6\%), and 52 (2.4\%) (Table 3).

Overall, hr.-HPV prevalence was strongly associated with HIV-1 serostatus ( $\mathrm{PR}=2.2$, 95\%CI: $1.7-2.8$ ). Table 4 show details of the bivariate analyses for hr.-HPV infection. Among HIV-1 seropositive women the main risk factor for hr.-HPV was age and male partner's lack of circumcision; among HIV-seronegative women, the main risk factor was the male partner's lack of circumcision $(\mathrm{RR}=1.9,95 \% \mathrm{CI}: 1.1-3.5, P=0.03)$, Table 4.

\section{Prevalence of, and risk factors associated with abnormal cytology}

The distribution of cytological results by HIV serostatus is shown in Table 1. The prevalence of abnormal cytology was higher among HIV-1 seropositive women (any SIL: $14.1 \%$ vs. $1.2 \%, P<0.0001$; low-grade SIL [LSIL]: $4.9 \%$ vs. $0.6 \%, P=0.02$; high-grade SIL [HSIL]: $1.8 \%$ vs. $0 \%$, $P=0.07)$. HPV35 was the most frequent hr.-HPV type associated with LSIL and above (LSIL+) (Fig. 1).
Table 3 HPV prevalence and genotype distribution among HIV-1 seropositive and HIV-seronegative women in Cape Coast, Ghana

\begin{tabular}{|c|c|c|c|}
\hline \multirow[t]{2}{*}{ HPV genotypes } & \multirow{2}{*}{$\begin{array}{l}\text { HIV-1 positive } \\
(N=160) \\
n(\%)\end{array}$} & \multirow{2}{*}{$\begin{array}{l}\text { HIV negative } \\
(N=169) \\
\mathrm{n}(\%)\end{array}$} & \multirow[t]{2}{*}{$P$-value } \\
\hline & & & \\
\hline HPV 16 & $17(10.6)$ & $1(0.6)$ & $<0.0001$ \\
\hline HPV 18 & $17(10.6)$ & $3(1.8)$ & 0.001 \\
\hline HPV 31 & $13(8.1)$ & $1(0.6)$ & 0.001 \\
\hline HPV 33 & $8(5.0)$ & $7(4.1)$ & 0.71 \\
\hline HPV 35 & 19 (11.9) & $9(5.3)$ & 0.03 \\
\hline HPV 39 & $7(4.4)$ & $3(1.8)$ & 0.17 \\
\hline HPV 45 & $10(6.3)$ & $2(1.2)$ & 0.01 \\
\hline HPV 51 & $2(1.3)$ & $0(0.0)$ & 0.14 \\
\hline HPV 52 & 19 (11.9) & $4(2.4)$ & 0.001 \\
\hline HPV 56 & $13(8.1)$ & $6(3.6)$ & 0.07 \\
\hline HPV 58 & $18(11.3)$ & $7(4.1)$ & 0.01 \\
\hline HPV 59 & $8(5.0)$ & $2(1.2)$ & 0.04 \\
\hline HPV 68 & $15(9.4)$ & $3(1.8)$ & 0.002 \\
\hline Any HPV & $120(75.0)$ & $72(42.6)$ & $<0.0001$ \\
\hline Any hr.-HPV & $105(65.6)$ & $51(30.2)$ & $<0.0001$ \\
\hline $\begin{array}{l}\text { HPV 16/18 (bivalent } \\
\text { vaccine types) }\end{array}$ & $34(21.3)$ & $4(2.4)$ & $<0.0001$ \\
\hline $\begin{array}{l}\text { HPV 16/18/6/11 (quadrivalent } \\
\text { vaccine types) }\end{array}$ & $53(33.1)$ & $7(4.1)$ & $<0.0001$ \\
\hline $\begin{array}{l}\text { HPV 16/18/31/33/45/52/58/6/11 } \\
\text { (nonavalent vaccine types) }\end{array}$ & 89 (55.6) & $29(17.2)$ & $<0.0001$ \\
\hline Low risk types only & $15(9.4)$ & $21(12.4)$ & 0.38 \\
\hline HPV 6 & $12(7.5)$ & $1(0.6)$ & 0.001 \\
\hline HPV 11 & $10(6.3)$ & $2(1.2)$ & 0.01 \\
\hline HPV 6 and/or 11 & $21(13.1)$ & $3(1.8)$ & $<0.0001$ \\
\hline \multicolumn{4}{|l|}{ Multiple types } \\
\hline $2-5$ & $64(52.5)$ & $36(21.3)$ & $<0.0001$ \\
\hline$>5$ & $13(8.1)$ & $0(0.0)$ & $<0.0001$ \\
\hline
\end{tabular}

Among HIV-1 seropositive women, having more than 4 pregnancies increased the risk of having LSIL+ abnormalities $(\mathrm{aOR}=4.1,95 \%$ CI: 1.1-17.0), while CD4+ count $>350$ cells $/ \mathrm{mm}^{3}$ decreased the risk $(\mathrm{aOR}=0.3$, 95\%CI: 0.07-0.9) (Table 5). HPV35 was the type most strongly associated with LSIL+, adjusting for age and HIV status $(\mathrm{aOR}=4.7,95 \% \mathrm{CI}: 1.3-17.7, P=0.02)$. There were too few HIV-seronegative women with SIL to conduct any meaningful risk factor analysis.

\section{Discussion}

This study reports for the first time the comparative prevalence and genotype distribution of HPV among HIV-1 seropositive and seronegative women in Ghana. Findings from research conducted mainly in developed countries and few 
Table 4 Factors associated with hr.-HPV infection in bivariate analyses, stratified by HIV serostatus

\begin{tabular}{|c|c|c|c|c|c|c|}
\hline \multirow[t]{2}{*}{ VARIABLES } & \multicolumn{3}{|l|}{ HIV-1 seropositive women } & \multicolumn{3}{|l|}{ HIV seronegative women } \\
\hline & hr-HPV $(N=105)$ n (\%) & RR $(95 \% \mathrm{Cl})$ & $P$-value & hr-HPV $(N=51) n(\%)$ & RR $(95 \% \mathrm{Cl})$ & $P$-value \\
\hline \multicolumn{7}{|l|}{ Age, years } \\
\hline$\leq 29$ & $10(90.9)$ & 1 & & $6(30.0)$ & 1 & \\
\hline $30-59$ & $89(64.0)$ & $0.6(0.5-0.7)$ & $<0.0001$ & $38(29.5)$ & $1.1(0.5-2.1)$ & 0.94 \\
\hline$>60$ & $6(60.0)$ & $0.5(0.3-0.9)$ & 0.02 & $7(35.0)$ & $1.2(0.5-3.2)$ & 0.64 \\
\hline \multicolumn{7}{|c|}{ Age at first sex, years categorical } \\
\hline$\leq 18$ & $48(57.8)$ & 1 & & $22(29.3)$ & 1 & \\
\hline$>18$ & $57(74.0)$ & $1.3(1.1-1.6)$ & 0.03 & 29 (30.9) & $1.1(0.7-1.7)$ & 0.83 \\
\hline \multicolumn{7}{|c|}{ Lifetime number of sexual partners } \\
\hline 1 & $9(81.8)$ & 1 & & $8(25.8)$ & 1 & \\
\hline$\geq 2$ & $96(64.4)$ & $0.9(0.6-1.2)$ & 0.49 & $43(31.2)$ & $1.2(0.6-2.3)$ & 0.57 \\
\hline \multicolumn{7}{|c|}{ Circumcision status of main/current partner } \\
\hline Circumcised & $97(64.7)$ & 1 & & $45(28.5)$ & 1 & \\
\hline Not circumcised & $8(80.0)$ & $1.4(1.2-1.6)$ & $<0.0001$ & $6(54.6)$ & $1.9(1.1-3.5)$ & 0.03 \\
\hline \multicolumn{7}{|l|}{ Smoking history } \\
\hline Never smoked & $101(65.2)$ & 1 & & $50(29.9)$ & 1 & \\
\hline Smokers (Ex/current) & $4(80.0)$ & $1.2(0.8-1.9)$ & 0.38 & $1(50.0)$ & $1.7(0.9-3.8)$ & 0.47 \\
\hline \multicolumn{7}{|c|}{ Hormonal contraceptive history } \\
\hline Ever used & $40(63.5)$ & 1 & & $23(32.4)$ & 1 & \\
\hline Never used & $65(67.0)$ & $1.1(0.8-1.3)$ & 0.66 & $28(28.6)$ & $0.9(0.6-1.4)$ & 0.63 \\
\hline
\end{tabular}

studies across Africa have shown a higher prevalence of HPV infection (any HPV, hr.-HPV, multiple HPV) among HIV-1-seropositive compared with HIV-seronegative women [7, 35-37]. In Ghana as elsewhere, HIV-1 seropositive women were significantly more frequently infected with HPV, and twice more likely to have high-risk and multiple HPV genotypes. The absolute hr.-HPV prevalence among HIV-1 seropositive women $(66.8 \%)$ is much higher than that reported by Ezechi et al. [36] in a study conducted among $220 \mathrm{HIV}-1$ seropositive and 295 HIV-seronegative women in Nigeria, which reported hr.-HPV prevalence of $24.6 \%$ and $15.9 \%$ in the respective groups. Another study in South Africa reported a twice higher prevalence of any hr.HPV infection among $145 \mathrm{HIV}-1$ seropositive and 107 HIV-seronegative women (68\% versus $31 \%$ ) [38], which is comparable to this study. Some of the differences in prevalence may be attributable to the HPV detection assay used [39], with genotyping assays such as the Anyplex-II HPV 28 used in this study more likely to have higher sensitivity. In addition, the population in this study had relatively low nadir CD4+ count $\left(<350\right.$ cells $\left./ \mathrm{mm}^{3}\right)$ and a worse WHO HIV/AIDS score III/IV (50\%) hence more likely to have higher HPV prevalence.

\section{HPV genotype prevalence and associated risk factors} Since protection afforded by HPV vaccines is essentially type specific $[40,41]$, knowledge of the genotype distribution in a specific population has implications for vaccine choice and predicted impact. The most prevalent hr.-HPV type in both groups in this study was HPV35, which none of the available vaccines on the market includes. The quadrivalent HPV vaccine is used in most countries and covers for only HPV6, 11, 16 and 18 [42, 43]. The recent introduction of the nonavalent vaccine to cover for additional HPV31, 33, 45, 52 and 58 may lead to a change in vaccine choice among countries and countries yet to implement wide scale or routine vaccination programs including Ghana.

HPV16 and 18 are said to contribute to about $70 \%$ of cervical cancer cases [44] and this has influenced vaccine development. This study demonstrated the association between HPV35 and abnormal cytology in Ghana. A study in neighbouring Burkina Faso found HPV35 to be the second most prevalent among sex workers with high prevalence of HIV [37]. Another study conducted in South Africa reported HPV35 as the third most prevalent genotype identified among 154 HIV-seronegative women with ICC [45]. Pirek et al. [46] found HPV35 the fifth commonest among Cameroonian women with ICC and HPV45 was the second most prevalent type. Maranga et al. [47] in their study among Kenyan women also found that HPV45 contributed significantly to cervical cancer among HIV-seropositive women. Attoh et al., [25] in 


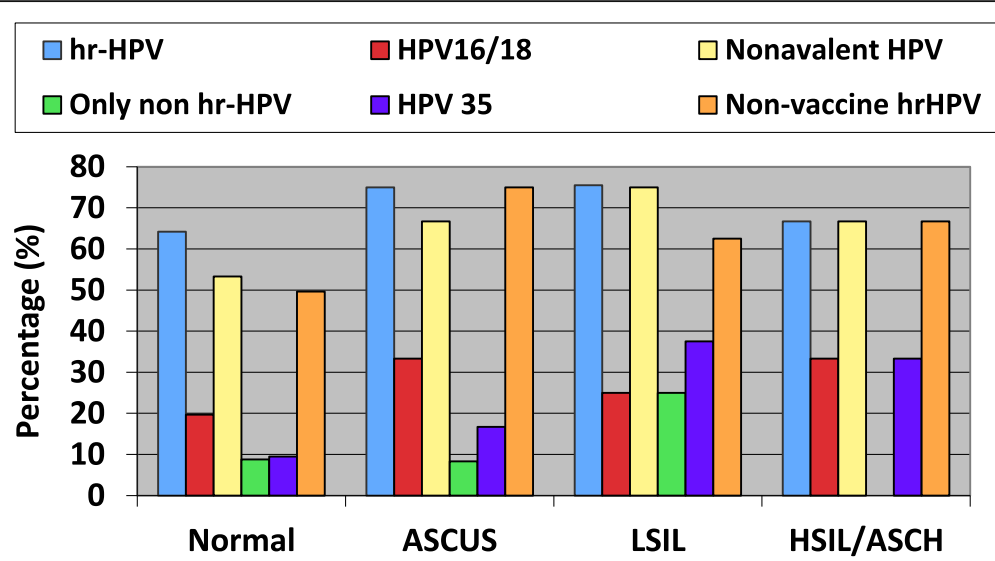

Fig. 1 High-risk HPV genotypes prevalence by cytological category, for HIV-1 seropositive women $(N=163)$. Figure legend: ASCUS = Atypical Squamous Cells of Undetermined Significance, LSIL = Low Grade Squamous Intraepithelial Lesions, HSIL = High Grade Squamous Intraepithelial Lesions

their study among Ghanaian women with cervical cancer detected 8 h-HPV genotypes $(16,18,35,39$, 45, 52, 56 and 66) with HPV18 being the most prevalent. Another study based in sub-Saharan Africa with inclusion of samples from Ghana found that HPV type distribution appeared to differ according to tumor type and HIV status and HPV16, 18, 45 and 35 were the most common HPV types in women with ICC [48]. In this study, hr.-HPV types included in the bi- or quadrivalent vaccines (HPV16/18) and nonavalent vaccine (HPV16/18/31/33/45/52 and 48) were found in higher proportions among HIV-1 seropositive compared with HIV-seronegative women.

Among study participants, there was evidence of an association between having hr.-HPV infection and younger age among HIV positive participants and lack of circumcision of the male partner among both HIV positive and negative groups. These findings are consistent with existing literature $[49,50]$. Other studies in Ghana and other parts of the world have reported association between employment status, marital status and educational level with HPV $[51,52]$.

Table 5 Bivariate and multivariate analyses of low-grade squamous intraepithelial lesions and higher (LSIL+) among HIV-1 seropositive women in Cape Coast, Ghana

\begin{tabular}{|c|c|c|c|c|c|}
\hline VARIABLES & LSIL+, n (\%) & OR $(95 \% \mathrm{Cl})$ & $P$-value & ${ }^{\mathrm{a}} \mathrm{AOR}(95 \% \mathrm{Cl})$ & $P$-value \\
\hline \multicolumn{6}{|l|}{ Age, years } \\
\hline$\leq 44$ & $7(7.9)$ & 1 & & $0.5(0.1-1.8)$ & 0.34 \\
\hline$\geq 45$ & $4(5.4)$ & $0.6(0.2-2.4)$ & 0.53 & & \\
\hline \multicolumn{6}{|l|}{ Education } \\
\hline$\leq 6$ years of formal education & $7(9.7)$ & 1 & & $0.5(0.2-1.9)$ & 0.30 \\
\hline$>6$ years of formal education & $4(4.4)$ & $0.4(0.1-1.5)$ & 0.18 & & \\
\hline \multicolumn{6}{|l|}{ Employment } \\
\hline Unemployed & $2(14.3)$ & 1 & & & \\
\hline Employed & $9(6.0)$ & $0.4(0.1-2.0)$ & 0.24 & & \\
\hline \multicolumn{6}{|l|}{ Smoking history } \\
\hline Never smoked & $10(6.3)$ & 1 & & & \\
\hline Smokers (Ex/current) & $1(20.0)$ & $3.7(1.4-16.9)$ & 0.23 & & \\
\hline \multicolumn{6}{|l|}{ Number of pregnancies } \\
\hline$\leq 4$ & $3(3.3)$ & 1 & & $4.1(1.1-17.0)$ & 0.05 \\
\hline$>4$ & $8(11.1)$ & $3.7(0.9-14.7)$ & 0.05 & & \\
\hline \multicolumn{6}{|l|}{ Nadir CD4+ count, cells $/ \mathrm{mm}^{3}$} \\
\hline$\leq 350$ & $10(8.9)$ & 1 & & $0.3(0.07-0.9)$ & 0.04 \\
\hline$>350$ & $1(2.3)$ & $0.2(0.03-2.0)$ & 0.15 & & \\
\hline
\end{tabular}

adjusted for age, level of education, total number of pregnancies and nadir CD4 count 


\section{Epidemiology of cytological abnormalities and associated risk factors}

Compared with HIV-seronegative women, HIV-1 seropositive women in this study had a higher prevalence of SIL and higher grade cytological lesions. Indeed, HSIL/ ASC-H were only identified among HIV-1 seropositive women. A study conducted among women in selected communities in the Ashanti region of Ghana found any SIL prevalence ranging between 3.5\% and 12.6\% [53], although this study did not report HIV status. Elsewhere in sub-Saharan Africa, Hood et al. reported that cervical lesions were significantly associated with the detection of plasma HIV RNA (with an adjusted relative risk of 1.16, 95\% CI: 1.05-1.28) among women in Senegal [54]. Another study in Kenya among 267 HIV-seropositive women on ART found a much higher prevalence of abnormal cytology of $46 \%$. The median duration of antiretroviral therapy was 13 months (IQR: 8-19) [55]. In another study conducted in South Africa among 109 HIV-seropositive women before initiation of ART, the prevalence of abnormal cytology was $66.3 \%$. The median CD4 count among these women was very low at $125 \mathrm{cells} / \mathrm{mm}^{3}$ [56].

In the sub-group analysis for HIV-1 seropositive women, factors which showed strong evidence of an association with SIL included nadir CD4+ T-cell count. A higher CD4+ T-cell count reflects a stronger immune system, which may be associated with greater ability to clear HPV infection compared with women who acquire HPV whilst more seriously immunocompromised, which may lead to more frequent persistence and a greater chance to develop lesions. The association with nadir CD4+ T-cell count has been demonstrated in other studies $[5,6,36]$. This study had some limitations. It was facility-based, which allowed for more convenience in recruitment, but its results may not be generalizable. Histology confirmation of lesions would have also been preferable as it is more specific diagnosis than cytology, although this has been a usual limitation of several epidemiological studies in sub-Saharan Africa. An important limitation is the unavailability of current HIV viral load and CD4 count for the HIV positive participants. Nonetheless, this study brings useful information for decision makers in the country, demonstrating that the burden of HPV infection and hr.-HPV infection is high in Ghana. The study also showed that the most prevalent HPV genotype was HPV35, and that among HIV-seronegative women, HPV16 and 18 were not among the top five most prevalent genotypes. The established contribution from HPV 16 and 18 has appropriately informed vaccine choices, nevertheless, the genotype distribution pattern found in this and other studies imply the need to look carefully at vaccine choices for primary prevention of HPV and cervical cancer among women in Ghana.

\section{Conclusion}

The study shows the need for a systematic national cervical cancer screening program in view of the high HPV prevalence even among the HIV seronegative women. This may include scheduled screening for women in Ghana using Pap smear, visual inspection (VIA) and the possibility of HPV screening. For HIV positive women, screening using HPV testing may be challenging since over $50 \%$ of them may be positive. Strong cervical cancer prevention and screening programs should be specifically deployed targeting HIV-seropositive women in Ghana. In addition, it demonstrates that prophylactic vaccination of young girls with the nonavalent HPV vaccine is likely the best means of cervical cancer prevention in Ghana.

\section{Additional file}

Additional file 1: Questionnaire for collecting data from study participants. This is the questionnaire which was administered to all recruited women before sample collection towards this epidemiology study. (DOCX $51 \mathrm{~kb}$ )

\section{Abbreviations}

ART: Anti-Retroviral Therapy; ASCUS: Atypical Squamous Cells of Undetermined Significance; CCTH: Cape Coast Teaching Hospital; CD4 + : Activated T-lymphocytes CD4; Cl: Confidence Interval; CIN: Cervical Intraepithelial Neoplasia; HIV: Human Immunodeficiency Virus; HPV: Human Papilloma Virus; hr.-HPV: High-Risk Human Papilloma Virus; H-SIL: High Grade Squamous Intraepithelial Lesion; ICC: Invasive cervical carcinoma;

KNUST: Kwame Nkrumah University of Science and Technology; LSIL: Low Grade Squamous Intraepithelial Lesion; PLHIV: People Living with HIV;

SIL: Squamous Intraepithelial Lesion; SSA: Sub Saharan Africa; STI: Sexually Transmitted Infection; VIA: Visual Inspection with Acetic acid; VILI: Visual Inspection with Lugol's iodine; WHO: World Health Organization; WLHA: Women Living with HIV/AIDS

\section{Acknowledgements}

We wish to thank staff at CCTH who helped with recruitment and follow up management of the women, in particular Mr. Ebenezer Aniakwa. The Commonwealth Secretariat Commission, UK, provided support to Dr. Dorcas Obiri-Yeboah to study at Kwame Nkrumah University of Science and Technology, Kumasi, Ghana and at the London School of Hygiene \& Tropical Medicine, UK.

\section{Funding}

The University of Cape Coast, Ghana provided the main source of funding for the research work (with no direct contribution to the content of this manuscript).

\section{Availability of data and materials}

The data set based on which results are generated is available upon reasonable request from the corresponding author.

\footnotetext{
Authors' contributions

OYD: study concept and design, participants recruitment and sample collection, laboratory testing (HPV genotyping), data entry and analysis, manuscript writing. AKP: proposal development, laboratory method (cytology), manuscript writing. MM: proposal development, laboratory methods, manuscript writing. ADE: data entry and analysis, manuscript writing. AG: participants recruitment and sample collection, manuscript writing. ASD: proposal development, laboratory testing, data entry and analysis, manuscript writing. ASY: study concept and design, data review/ interpretation of research findings, manuscript writing. MP: study concept and design, data review/interpretation of research findings, manuscript writing. All authors read and approved the final manuscript.
} 


\section{Ethics approval and consent to participate}

Ethical approval was obtained from the Committee on Human Research Publications and Ethics (CHRPE) of the School of Medical Sciences (SMS), Kwame Nkrumah University of Science and Technology (KNUST). Study participants signed or thumb printed written informed consent indicating consent to participate.

\section{Consent for publication}

Not applicable.

\section{Competing interests}

The authors declare no competing interest be it financial or non-financial.

\section{Publisher's Note}

Springer Nature remains neutral with regard to jurisdictional claims in published maps and institutional affiliations.

\section{Author details}

'Department of Microbiology and Immunology, School of Medical Sciences, University of Cape Coast, Cape Coast, Ghana. ${ }^{2}$ Department of Pathology, School of Medical Sciences, University of Cape Coast, Cape Coast, Ghana. ${ }^{3}$ Department of Clinical Microbiology, School of Medical Sciences, Kwame Nkrumah University of Science and Technology, Kumasi, Ghana. ${ }^{4}$ Mineworkers Union of Trade Union Congress, Tarkwa, Ghana. ${ }^{5}$ Department of Obstetrics and Gynaecology, Cape Coast Teaching Hospital, Cape Coast, Ghana. ${ }^{6}$ Department of Clinical Research, Faculty of Infectious and Tropical Diseases, London School of Hygiene and Tropical Medicine, London, UK.

\section{Received: 4 October 2016 Accepted: 10 October 2017}

Published online: 16 October 2017

\section{References}

1. zur Hausen H. Papillomaviruses and cancer: from basic studies to clinical application. Nat Rev Cancer. 2002;2(5):342-50.

2. Burd EM. Human Papillomavirus and cervical cancer. Clin Microbiol Rev. 2003;16(1):1-17

3. Denny LA, et al. Human papillomavirus, human immunodeficiency virus and immunosuppression. Vaccine. 2012;30(Suppl 5):F168-74.

4. Meyrelles ARI, et al. Bonafide, type-specific human papillomavirus persistence among HIV-positive pregnant women: predictive value for cytological abnormalities, a longitudinal cohort study. Mem Inst Oswaldo Cruz. 2016;111(2):120-7.

5. Grinsztejn B, et al. Factors associated with increased prevalence of human papillomavirus infection in a cohort of HIV-infected Brazilian women. Int J Infect Dis. 2009;13(1):72-80

6. Konopnicki D, et al. Sustained viral suppression and higher CD4+ T-cell count reduces the risk of persistent cervical high-risk human papillomavirus infection in HIV-positive women. J Infect Dis. 2013;207(11):1723-9.

7. Blitz S, et al. Evaluation of HIV and highly active antiretroviral therapy on the natural history of human papillomavirus infection and cervical cytopathologic findings in HIV-positive and high-risk HIV-negative women. J Infect Dis. 2013;208(3):454-62.

8. Adler $\mathrm{DH}$, et al. Increased regression and decreased incidence of human papillomavirus- related cervical lesions among HIV-infected women on HAART. AIDS. 2012;26(13):1645-52.

9. Firnhaber $C$, et al. Highly active antiretroviral therapy and cervical dysplasia in HIV-positive women in South Africa. J Int AIDS Soc. 2012:15(2):17382.

10. Minkoff $H$, et al. Influence of adherent and effective antiretroviral therapy use on human papillomavirus infection and squamous intraepithelial lesions in human immunodeficiency virus-positive women. J Infect Dis. 2010;201(5):681-90.

11. Konopnicki D, De Wit S, Clumeck N. HPV and HIV coinfection: a complex interaction resulting in epidemiological, clinical and therapeutic implications. Futur Virol. 2013;8(9):903-15.

12. De Vuyst $H$, et al. Prevalence and determinants of human papillomavirus infection and cervical lesions in HIV-positive women in Kenya. Br J Cancer. 2012;107(9):1624-30

13. Firnhaber $C$, et al. Association between cervical dysplasia and human papillomavirus in HIV seropositive women from Johannesburg South Africa. Cancer Causes Control. 2010;21(3):433-43.
14. Watson-Jones $D$, et al. High prevalence and incidence of human papillomavirus in a cohort of healthy young African female subjects. Sex Transm Infect. 2013;89(5):358-65.

15. Asiaf A, et al. Review of the current knowledge on the epidemiology, pathogenesis, and prevention of human papillomavirus infection. Eur J Cancer Prev. 2014;23(3):206-24.

16. Carozzi F, et al. Age and geographic variability of human papillomavirus high-risk genotype distribution in a large unvaccinated population and of vaccination impact on HPV prevalence. J Clin Virol. 2014;60:257-63.

17. Gadducci A, et al. Smoking habit, immune suppression, oral contraceptive use, and hormone replacement therapy use and cervical carcinogenesis: a review of the literature. Gynecol Endocrinol. 2011;27(8):597-604.

18. Appleby $P$, et al. Cervical cancer and hormonal contraceptives: collaborative reanalysis of individual data for 16,573 women with cervical cancer and 35,509 women without cervical cancer from 24 epidemiological studies. Lancet. 2007;370(9599):1609-21.

19. Moreno $\mathrm{V}$, et al. Effect of oral contraceptives on risk of cervical cancer in women with human papillomavirus infection: the IARC multicentric casecontrol study. Lancet. 2002:359(9312):1085-92.

20. Shew ML, et al. Association of Chlamydia trachomatis infection with redetection of human papillomavirus after apparent clearance. J Infect Dis. 2013;208(9):1416-21.

21. Paba P, et al. Co-expression of HSV2 and Chlamydia trachomatis in HPVpositive cervical cancer and cervical intraepithelial neoplasia lesions is associated with aberrations in key intracellular pathways. Intervirology. 2008; 51(4):230-4.

22. Bosch FX, Albero G, Castellsague X. Male circumcision, human papillomavirus and cervical cancer: from evidence to intervention. J Fam Plann Reprod Health Care. 2009;35(1):5-7

23. Forman D, et al. Global burden of human papillomavirus and related diseases. Vaccine. 2012;30(Suppl 5):F12-23.

24. Brandful JAM, et al. Oncogenic human papillomavirus (HPV) in women from Ghana. J Cancer Res Exp Oncol. 2014;6(4):31-8.

25. Attoh $\mathrm{S}$, et al. Human papilloma virus genotypes in Ghanaian women with cervical carcinoma. East Afr Med J. 2010;87(8):345-9.

26. Quentin W, et al. Costs of cervical cancer screening and treatment using visual inspection with acetic acid (VIA) and cryotherapy in Ghana: the importance of scale. Tropical Med Int Health. 2011;16(3):379-89.

27. de Sanjose $\mathrm{S}$, et al. Human papillomavirus genotype attribution in invasive cervical cancer: a retrospective cross-sectional worldwide study. Lancet Oncol. 2010;11(11):1048-56.

28. Group, T.F.I.S. Quadrivalent vaccine against human Papillomavirus to prevent high-grade cervical lesions. N Engl J Med. 2007;356(19):1915-27.

29. Joura EA, et al. A 9-Valent HPV vaccine against infection and intraepithelial Neoplasia in women. N Engl J Med. 2015;372(8):711-23.

30. Harper DM, Williams KB. Prophylactic HPV vaccines: current knowledge of impact on gynecologic premalignancies. Discov Med. 2010;10(50):7-17.

31. Bouvard V, et al. A review of human carcinogens; part B: biological agents Lancet Oncol. 2009:10(4):321-2.

32. Kwon MJ, et al. Comparison of the Anyplex II HPV28 assay with the hybrid capture 2 assay for the detection of HPV infection. J Clin Virol. 2014;59:246-9.

33. Solomon D, et al. The 2001 Bethesda system: terminology for reporting results of cervical cytology. JAMA. 2002;287(16):2114-9.

34. Darragh TM, et al. The lower Anogenital Squamous terminology standardization project for HPV-associated lesions: background and consensus recommendations from the College of American Pathologists and the American Society for Colposcopy and Cervical Pathology. J Low Genit Tract Dis. 2012;16(3):205-42.

35. Park EK, et al. Human Papillomavirus prevalence and genotype distribution among HIV-infected women in Korea. J Korean Med Sci. 2014;29(1):32-7.

36. Ezechi $O C$, et al. The burden, distribution and risk factors for cervical oncogenic human papilloma virus infection in HIV positive Nigerian women. Virol J. 2014:11(1):5.

37. Didelot-Rousseau MN, et al. Human papillomavirus genotype distribution and cervical squamous intraepithelial lesions among high-risk women with and without HIV-1 infection in Burkina Faso. Br J Cancer. 2006;95(3):355-62.

38. Mbulawa ZZ, et al. Genital human papillomavirus prevalence and human papillomavirus concordance in heterosexual couples are positively associated with human immunodeficiency virus coinfection. J Infect Dis. 2009;199(10):1514-24 
39. Rebolj M, et al. Disagreement between human Papillomavirus assays: an unexpected challenge for the choice of an assay in primary cervical screening. PLoS One. 2014;9(1):e86835.

40. Lowy DR, et al. Human papillomavirus infection and the primary and secondary prevention of cervical cancer. Cancer. 2008;113(7 Suppl):1980-93.

41. Roden R, et al. Assessment of the serological relatedness of genital human papillomaviruses by hemagglutination inhibition. J Virol. 1996;70:3298-301.

42. Anastasiou-Fotaki P, Deligeoroglou E, Kreatsas G. The GARDASIL vaccine can prevent cervical carcinoma caused by human papilloma virus (HPV) (results from our participation and from the study carried out in Greece). Akush Ginekol (Sofiia). 2007:46(3):17-20.

43. Fairley CK, et al. Rapid decline in presentations of genital warts after the implementation of a national quadrivalent human papillomavirus vaccination programme for young women. Sex Transm Infect. 2009;85(7):499-502.

44. de Sanjose S, et al. Age-specific occurrence of HPV16- and HPV18-related cervical cancer. Cancer Epidemiol Biomark Prev. 2013;22(7):1313-8.

45. van Aardt MC, et al. Unique human Papillomavirus-type distribution in south African women with invasive cervical cancer and the effect of human immunodeficiency virus infection. Int J Gynecol Cancer. 2015;25:919.

46. Pirek D, et al. Human papillomavirus genotype distribution among Cameroonian women with invasive cervical cancer: a retrospective study. Sex Transm Infect. 2015:91:440.

47. Maranga IO, et al. HIV infection alters the Spectrum of HPV subtypes found in cervical smears and carcinomas from Kenyan women. Open Virol J. 2013;7:19.

48. Denny $L$, et al. Human papillomavirus prevalence and type distribution in invasive cervical cancer in sub-Saharan Africa. Int J Cancer. 2014;134(6): 1389-98.

49. Mitchell SM, et al. Factors associated with high-risk HPV positivity in a lowresource setting in sub-Saharan Africa. Am J Obstet Gynecol. 2014;210(1):81. e1-81.e7

50. Louie KS, de Sanjose S, Mayaud P. Epidemiology and prevention of human papillomavirus and cervical cancer in sub-Saharan Africa: a comprehensive review. Tropical Med Int Health. 2009;14(10):1287-302.

51. Domfeh A, et al. Cervical human papillomavirus infection in Accra, Ghana. Ghana Med J. 2008:42(2):71-8.

52. Brankovic I, Verdonk $P$, Klinge I. Applying a gender lens on human papillomavirus infection: cervical cancer screening, HPV DNA testing, and HPV vaccination. Int J Equity Health. 2013;12:14.

53. Handlogten KS, et al. Cervical cancer screening in Ghana, west Africa: prevalence of abnormal cytology and challenges for expanding screening. Int J Gynecol Pathol. 2014;33(2):197-202.

54. Hood JE, et al. The association between HPV, intraepithelial lesions and HIV-1 shedding in anogenital specimens in two contrasting populations: Senegalese women and American MSM. Int J STD AIDS. 2015;27(5):353-62.

55. McKenzie KP, et al. Cervical squamous intraepithelial lesions among HIV-positive women on antiretroviral therapy in Kenya. Curr HIV Res. 2011;9(3):180-5.

56. Moodley JR, et al. Human papillomavirus prevalence, viral load and pre-cancerous lesions of the cervix in women initiating highly active antiretroviral therapy in South Africa: a cross-sectional study. BMC Cancer. 2009:9:275.

\section{Submit your next manuscript to BioMed Central and we will help you at every step:}

- We accept pre-submission inquiries

- Our selector tool helps you to find the most relevant journal

- We provide round the clock customer support

- Convenient online submission

- Thorough peer review

- Inclusion in PubMed and all major indexing services

- Maximum visibility for your research

Submit your manuscript at www.biomedcentral.com/submit 